\title{
ДЕТСКАЯ БОЛЕЗНЬ «ЛЕВИЗНЫ» В ГЛОБАЛИЗМЕ
}

Acharya A., Buzan B. The Making of Global International Relations: Drigins and Evolution of IR at its Centenany. Cambridge University Press, 2019. 392 p.

Ачария А., Бузан Б. Создание глобальных международных отношений: возникновение и развитие дисципЛины в течение последних ста лет. Кембридж юнивёрсити пресс, 2॰19. उ92 c.

Казалось бы, как могут быть связаны книга современных теоретиков международных отношений и труд «вождя мирового пролетариата», отсылка к названию которого присутствует в заголовке рецензии ${ }^{1}$ ? Оба автора монографии, опубликованной издательством Кембриджского университета, до сих пор работали за рамками марксистской традиции. Барри Бузан - важнейший современный представитель «английской школы», в то время как Амитав Ачария - один из видных исследователейпостколониалистов.

Тем не менее сравнение их недавней публикации с произведением В.И. Ленина напрашивается сразу по трём причинам. Bo-nервых, и в том, и в другом случае выявляются симптомы интеллектуальной ограниченности доминирующих концепций и подходов: левизна и меньшевизм в коммунистическом учении; гегемонистский западоцентризм - в исследованиях международных отношений. Во-вторых, и В.И. Ленин, и А. Ачария с Б. Бузаном предлагают способы выхода из тупика, в который заводят господствующие парадигмы (ориентация на большевизм в первом случае и создание глобальной теории во втором). B-третьих, обе работы призывают искать ресурсы для искоренения существующих недостатков на периферии капиталистической системы, а не в её ядре. Реф- реном в обеих работах проходит цитата из Карла Каутского, приводимая В.И. Лениным: «Революционный центр передвигается с запада на восток» [Ленин 1974: 5].

Однако если опора на марксистскую онтологию, методологию и эпистемологию ожидаема для лидера большевизма и он к ним открыто апеллирует [Ленин 1974: 7-8], то в книге А. Ачарии и Б. Бузана они присутствуют исподволь. Между тем создание глобальной теории международных отношений - проект если не чисто марксистский, то абсолютно левый. В этой связи авторы предлагаемой рецензии попробуют деконструировать «левизну» глобализма А. Ачарии и Б. Бузана.

В 2019 г. отмечается столетие создания первой кафедры международной политики в Университете Аберистуита, и годовщина условной даты основания теории международных отношений постулируется исследователями в качестве побудительного мотива написания книги. В первую очередь их работа направлена на развенчание «мифа 1919 года» - авторы представляют альтернативную версию истории развития дисциплины, начавшей свой отсчёт задолго до Первой мировой войны.

Кроме того, представленный в книге нарратив должен продемонстрировать тесную связь международных отношений (как системы реально осуществляемых прак-

${ }^{1}$ Имеется в виду [Ленин 1974]. 
тик, которые авторы обозначают с маленькой буквы - “international relations") и дисциплины о международных отношениях ("International Relations"). Тем самым А. Ачария и Б. Бузан стремятся обосновать прямую последовательность - порядок, утвердившийся в мире после восхождения Запада в XIX веке, воспроизводился и в теоретическом осмыслении. Теория международных отношений $(I R)$ основана на тех же западных идеологиях, что и международные отношения современности (ir of modernity): либерализм, социализм, национализм и научный расизм (с. 11). Каждая из идеологий определяла как мировую и национальные политики, так и представления теоретиков о мире вокруг и международной политике. Именно эти идеологии влияли на отбор как ключевых концептов, так и методов изучения и применения этих концептов.

Между тем книга стремится осветить развитие исследований международных отношений вне западного мира, обосновав тем самым несправедливость замалчивания научной мысли развивающихся стран. Авторы отмечают, что «дисциплина о международных отношениях во многом построена на убеждении, что история Запада и западная политическая мысль есть не что иное, как история всего мира и мировая политическая мысль» (с. 2).

Для доказательства выдвинутых утверждений в книге используется модель периодизации развития глобального международного сообщества (global international society), разработанная Б. Бузаном в сотрудничестве с датским исследователем Л. Шонборгом [Buzan, Schouenborg 2018]. В соответствии с ней можно выделить три хронологически сменявших друг друга подтипа таких сообществ (с. 5-6). Основным критерием для выделения отдельных периодов выступает стабильность гегемонии Запада. После Второй мировой войны произошёл её пересмотр, что привело к эрозии западоцентризма, но только с 2008 г. начал складываться плюралистический мир.

Под гегемонией в данном случае понимается материальное и идейное доминиро- вание западных стран во главе с Великобританией и Францией, а затем США во всём мире. Речь, прежде всего, идет о незападном мире, в котором Лондон, Париж и Вашингтон старались играть определяющую «цивилизаторскую» роль. В плюралистическом мире, напротив, существуют различные равновеликие центры материальной и идейной силы, определяющие развитие как регионов, в которых находятся, так и всего мира.

Параллельно с эволюцией глобального сообщества происходила трансформация теории международных отношений. Несмотря на то что развитие исследовательской дисциплины отражало происходящие в мировой политике процессы, «в дисциплине о международных отношениях $(I R)$ западное доминирование сохранялось гораздо дольше, чем в международных отношениях (ir)» (c. 5).

Этапы эволюции глобального сообщества рассматриваются авторами в хронологической последовательности. Сначала представляются идеациональные и материальные характеристики соответствующего временного периода (и в центре, и на периферии), затем - то, как они влияли на развитие теории международных отношений в западных и незападных странах. Первый этап в развитии глобального сообщества, продолжавшийся до середины XX века, разбивается на два подпериода: «долгий девятнадцатый век» (1789-1914) и межвоенный период (1919-1939). Отдельно рассматриваются Первая и Вторая мировые войны, которые представляются в качестве триггеров перехода международных отношений в новое состояние. Второй этап включает в себя «холодную войну» (19451989), а также последующие за ней два десятилетия (1989-2008). По мнению авторов, после 2008 г. произошёл переход к третьему этапу эволюции глобального сообщества.

Значительная часть выводов книги связана с выделением особенностей того типа глобального сообщества, который оформился после «глобальной рецессии», а также соответствующей ему теории междуна- 
родных отношений. Авторы предлагают называть возникшую ситуацию «постзападной». По их мнению, «Запад не исчезнет, как когда-то исчез Великий Рим, а лишь станет одним из центров богатства, власти и культурных стандартов» (с. 264). Переход к новому состоянию будет происходить через установление «заложенного плюрализма» (embedded pluralism). Он предполагает не только существование разнообразия, принимаемого участниками глобального сообщества (такую ситуацию авторы называют «глубинным плюрализмом» (deep pluralism)), но и его восприятие как основы развития международной системы (с. 265). Наблюдаемый «оспариваемый плюрализм» (contested pluralism), характеризующийся активным сопротивлением ряда игроков (в первую очередь Соединённых Штатов) установлению нового мирового порядка, по мнению авторов, не станет препятствием на пути к построению постзападного мира.

Что касается становления постзападных исследований международных отношений, то «за исключением постколониализма, все теории остаются западоцентристскими, а дисциплина - исключительно западной» (с. 285). Вместе с тем растущее недовольство подобным положением дел среди специалистов (с. 287-295), с точки зрения авторов, рано и поздно приведёт к созданию «глобальной теории международных отношений», также характеризуемой «заложенным плюрализмом» (embedded pluralism). При этом в отличие от В.И. Ленина, описывающего особенности предлагаемой им альтернативы критикуемым концепциям, А. Ачария и Б. Бузан не дают ответа относительно того, как может выглядеть дисциплина будущего, появление которой они прогнозируют.

Неготовность представить собственную теоретическую конструкцию, способную сместить господствующую западоцентристскую парадигму, ослабляет убедительность аргументации авторов. Стремление заверить читателя, что за основу должна быть взята теория международного сообщества английской школы, дополнен- ная положениями постколониализма, имеет мало шансов на успех. В самой книге авторы оперируют в большей степени логикой мир-системного неомарксизма, прослеживая угнетение периферии центром не только в экономике, но и в сфере общественно-научного познания. Использование понятия «теория» в том виде, как его понимает Роберт Кокс (по мнению исследователя, «теория всегда существует для кого-то и ради какой-либо цели» [Cox 1981: 128]), опора на положения «критической теории» ещё больше отдаляют нас от теоретического пространства, в котором, по словам авторов, мы якобы всё ещё находимся.

Критическая теория развивалась последователями Франкфуртской школы, отстаивавшей обновление науки через марксистскую онтологию и эпистемологию. Несмотря на включение ряда постпозитивистских положений и наличие подхода Э. Линклатера, стремящегося соединить положения критической теории и английской школы, последняя всё-таки остаётся одной из традиционалистских теорий, которые Р. Кокс критикует.

Между тем попытки А. Ачарии и Б. Бузана сформулировать основания новой глобальной теории международных отношений оборачиваются очередной реинкарнацией неомарксистского проекта, соединяющим мир-системный анализ и грамшианскую концепцию идейной гегемонии. От английской школы в данном случае остаётся только терминология. Экономический детерминизм, превалирующий в аргументации авторов, также указывает на скрытую «левизну» их глобализма. Выбор мирового кризиса 2008 г. в качестве точки отсчёта нового глобального общества весьма показателен в этой связи. Хобсбаумовский взгляд на историческое развитие и отождествление истории глобальных сообществ с историей капитализма не могут остаться незамеченными, как и дихотомия «угнетатель-угнетаемый», выступающая метафорой неомарксизма.

Нельзя не отметить важность книги А. Ачарии и Б. Бузана. Она представляет 
попытку двух ведущих современных теоретиков определить направление дальнейшего развития дисциплины. В качестве основания выстраивания теорий в плюралистичном мире они заявляют необходимость диалога. Включение незападных концепций во всё ещё преимущественно западные исследования международных отношений обосновывается как путь дальнейшего обогащения дисциплины. Вместе с тем непроблематизированными положениями остаются «левизна» самого предлагаемого подхода и оптимистичное отношение к возможности гармоничного сосуществования в теории и в глобальном сообществе. Не до конца ясно, как будет проходить синтез глобальной теории. Возможно, для этого необходим «пятый великий спор», который пройдёт между западными и незападными концепциями. Говорить о скором создании как глобальной теории, так и постзападного сообщества в том виде, как они представлены в книге, всё-таки преждевременно.

Оксана Григорьева кандидат политических наук Никита Плюснин

\section{Список литературы}

Ленин В.И. Детская болезнь «левизны» в коммунизме // Полное собрание сочинений (5-е издание). Т. 41. М.: Изд-во политической литературы, 1974. С. 1-104.

Buzan B., Schouenborg L. Global International Society: A New Framework for Analysis. Cambridge: Cambridge University Press, 2018. 286 p.

Cox R.W. Social Forces, States and World Orders: Beyond International Relations Theory. Millennium. Vol. 10. №2. 1981. P. 126-155.

\section{References}

Lenin V.I. (1974). Detskaya bolezn' «levizny» v kommunizme [«Left-Wing» Communism: A Childhood Disease]. Complete works of Lenin (5 ${ }^{\text {th }}$ edition). Vol. 41. Moscow: Izdatel'stvo politicheskoj literatury. P. 1-104.

Buzan B., Schouenborg L. (2018). Global International Society: A New Framework for Analysis. Cambridge: Cambridge University Press. $286 \mathrm{p}$.

Cox R.W. (1981) Social Forces, States and World Orders: Beyond International Relations Theory. Millennium. Vol. 10. №2. P. 126-155. 